\title{
Experimental Investigation of the Dynamic properties of Nano-modified Interlayer Hybrid Composite with Graphene Oxide
}

\author{
Nagabhushan V Pujar ${ }^{1 *}$, Nanjundaradhya $\mathrm{N} \mathrm{V}^{2}$, Ramesh S Sharma ${ }^{2}$ \\ ${ }^{1}$ Research Scholar, R \& D Center, Department of Mechanical Engineering, R V College of Engineering, Bengaluru- 560 059, India \\ ${ }^{2}$ Professor, R \& D Center, Department of Mechanical Engineering, R V College of Engineering, Bengaluru- 560 059, India
}

\begin{abstract}
DOI: $10.36348 /$ sjet.2021.v06i01.001 $\quad$ | Received: 13.12.2020 | Accepted: 29.12.2020 | Published: 04.01 .2021
\end{abstract}
*Corresponding author: Nagabhushan V Pujar

\section{Abstract}

From the literature it is seen that graphene oxide nano filler possess exceptional mechanical properties and it is being used for enhancing mechanical properties in polymer composite. The effect of inclusion of graphene oxide nano filler on dynamic properties in fiber reinforced polymer composite has not been fully investigated. The objective of this experimental work is to investigate the dynamic properties of graphene oxide based nano-modified symmetric Glass/Carbon interlayer hybrid laminates. Ultra-sonification has been used for dispersing graphene oxide ( $0.5 \% \mathrm{wt})$ nano filler into the epoxy. The unidirectional carbon fibers are placed into the composite laminate at various stacking sequence. The modal parameters like frequency, mode shape and damping ratio were determined experimentally using traditional 'strike method' using FFT analyzer and Data Acquisition System. Experimental modal analysis of the composite laminates was conducted for fiber orientations of $45^{\circ}$ and for two boundary conditions ( ie F-F-F-F and C-F-FF). The effect of hybridization using graphene oxide nano filler in symmetric glass/carbon interlayer composite on frequency and modal damping are discussed in this paper. This research work provides basic understanding of the dynamic behavior of interlayer hybrid composites with incorporation of Graphene oxide.

Keywords: Hybrid composite, graphene oxide, modal, frequency, damping.

Copyright (C) 2021 The Author(s): This is an open-access article distributed under the terms of the Creative Commons Attribution 4.0 International License (CC BY-NC 4.0) which permits unrestricted use, distribution, and reproduction in any medium for non-commercial use provided the original author and source are credited.

\section{INTRODUCTION}

Hybrid composites are catching the attention of both academic researchers and the industries for their ability to provide enhanced mechanical properties at lesser cost. Hybrid composites can be broadly classified into interlayer, intraply \& tow-by-tow hybrid. The interlayer hybrid composite is the most commonly used and is fabricated with matrix composed of least two different types of fibers ie low elongation fiber and a high elongation fiber [1, 2]. The high elongation fiber fibers have the highest failure strain compared to the low elongation fibers. The aerospace, shipping and automobile industries are making use of hybrid composites. Some of these applications are likely to be exposed to dynamic loads resulting in vibration, undesirable noise and reduced life of component. The amplitudes of the vibrations can be reduced by dissipation of energy through passive damping. Though composites materials possess superior inherent damping compared to traditional engineering materials, the damping exhibited by conventional composites may not be adequate dissipate energy in some dynamic applications.
Damping behavior in composite materials can be enhanced by micro-mechanical means by changing parameters like as fiber orientation, fiber-matrix interphase, fiber aspect ratio, fiber-matrix interphase and by inclusion of nano fillers into matrix [3-5]. The experimental modal analysis of composites is necessary to predict their dynamic properties like natural frequency, damping and mode shapes. The knowledge of natural frequencies, mode shapes and damping ratio assists the engineers to design composite structure subjected to dynamic loads. However, there is an always a trade-off between the damping and stiff ness.

In last few years glass fibers are widely used in the industries for providing high tensile strength at lesser cost. On the other hand, carbon fibers which are very expensive compared to glass fibers are widely used for their excellent properties like high strength, modulus and lesser density [6, 7]. Composite material with balanced mechanical properties at optimal cost can be designed through hybridization of glass fibers and carbon fibers [7]. Most of the researchers are working on exploring the mechanical properties of the hybrid composites [8-10]. The literature on the evaluation of dynamic properties of hybrid composites are scarce. 
The vibration behavior of a drive shaft by using both carbon and glass fibers has been studied by Abu Taliba et al., [11]. It was observed that by changing the orientation of carbon fiber from $0^{\circ}$ to $90^{\circ}$ the frequency decreased by $44.5 \%$.

Didik Djoko et al., [12] reported that for hybrid composite the higher damping ratio was observed for carbon-glass fiber with $45^{\circ} / 45^{\circ}$ of fiber orientation.

Nayak et al., [13] have investigated experimentally the vibration properties of hybrid composites made up of glass and carbon fibres. They have observed that for hybrids composite the natural frequency was minimum for (G-C-G-G) stacking sequence containing $25 \%$ carbon fibers and $75 \%$ glass fibers and with $50 \%$ carbon \& glass fibers, the natural frequency was minimum for $(\mathrm{C}-\mathrm{G}-\mathrm{C}-\mathrm{G})_{2}$ stacking sequence.

Murugan et al., [14] reported that improvement in damping can be seen by hybridization of carbon with glass fiber. Hybrid composite with carbon fiber on the outside and glass towards the inside of the laminate displayed a higher storage modulus, loss modulus and loss factor.

The vibration characteristics were studied experimentally by Murugan et al., [15] using impulse excitation techniques on a hybrid composite beam comprising of glass \& carbon fiber. It was observed that the stacking sequence of glass/carbon fibers had a significant effect on the mechanical and dynamic properties.

In recent years nano fillers like SWCNT, MWCNT, Graphene and Graphene oxide are being assessed by research scholars for enhancing the mechanical properties of composites. The inclusion of Graphene oxide in polymer-based composites has shown enhancement in mechanical properties like strength, modulus \& toughness. The focus of the ongoing research activities using graphene oxide has been mostly on the assessment of static properties.

Liu et al., [16] observed that addition of carbonbased Graphene oxide nano filler to an epoxy exhibited resulted in improvement in flexural strength, modulus and storage modulus.

Guan et al., [17] have observed substantial enhancement in the mechanical properties of epoxy with addition of functionalized GO. With addition of a smaller quantity ie. $0.50 \mathrm{wt} \%$ Graphene oxide there was a improvement of $63 \%$ in tensile strength and $119 \%$ in toughness.

Galpaya et al., [18] has shown that Graphene oxide inclusion into the epoxy significantly enhanced the mechanical properties. The modulus of the composite enhanced by $\sim 35 \%$ when compared with neat epoxy for $0.5 \mathrm{wt} \%$ of Graphene oxide inclusion.

Pathak et al., [19] reported an increase of $66 \%$ in bending strength, $70 \%$ in flexural modulus for $0.3 \mathrm{wt} \%$ of graphene oxide inclusion in composites containing carbon fibers.

Nagabhushan et al., [20] have studied the effect of addition of graphene oxide on unidirectional GFRP composites. They observed that the inclusion of the GO nano filler displayed improvement in damping of laminates.

Rafie et al., [21] have experimentally investigated the vibration characteristics of laminated fiberglass/epoxy composites altered with multiwalled carbon nanotubes, graphene oxide, reduced-graphene oxide and graphene nanoplatelets. It was shown that at higher quantity of nanofillers the damping ratio increased and natural frequencies decreased.

Xiaoning et al., [22] reported that the addition of nanofillers helps in enhancing the frictional stick-slip mechanism and thereby improves the damping.

Few researchers are using experimentally methods for investigating the dynamic properties for hybrid composites. The effect of addition of carbon-based nano fillers like graphene oxide to symmetric interlayer hybrid composites comprising of glass/carbon fibers on the dynamic properties have not been explored. The objective of this work is to study the dynamic behavior of glass/carbon fiber interlayer hybrid symmetric laminate impregnated with $0.5 \% \mathrm{wt}$ of graphene oxide for various stacking sequence of carbon fibers. The influence of boundary conditions ie F-F-F-F and C-F-F-F on the dynamic properties are also investigated. The influence of fiber orientation of $45^{\circ}$ on the modal parameters are also studied.

\section{MATERIALS AND FABRICATION Materials Used}

Unidirectional Glass fiber (Style 92145), unidirectional Carbon fiber (Tenax 796), Araldite-LY556 resin and HY- 951 hardener are used for this experimental work. Graphene Oxide in powder form supplied by United Nanotech Innovations Pvt. Ltd, has been used.

\section{Fabrication of Laminates}

For this experimental work, two kinds of the composite laminates were fabricated. First kind is the pristine composite laminate comprising of epoxy-based UD glass fiber and other kind is interlayer hybrid laminates comprising of epoxy-based UD glass fiber, UD carbon fiber and Graphene oxide nano filler. The details of the composite laminates fabricated for this study are shown in Table 1. Interlayer Hybrid laminates were fabricated for various stacking sequence of carbon fibers as shown in Figure 1. The epoxy and hardener are mixed 
Nagabhushan V Pujar et al; Saudi J Eng Technol, Jan, 2021; 6(1): 1-8.

in the ratio of 10:1. Graphene oxide content of $0.5 \% \mathrm{wt}$ is used in the fabrication of each of the interlayer hybrid composites. Ultra-sonification has been used for evenly mixing the graphene oxide into epoxy. The traditional 'hand lay-up' method followed by vacuum bagging process is used for the fabrication of all the composite laminates. After fabrication the laminates are cured in oven at $100^{\circ} \mathrm{C}$ for 60 minutes.

\section{Specimen Preparation}

The specimens required for the experimental modal testing are machined from the laminate using diamond tipped cutter. Specimen dimensions are $150 \mathrm{~mm} \times 150 \mathrm{~mm}$ for F-F-F-F boundary condition and $170 \mathrm{~mm} \times 150 \mathrm{~mm}$ for C-F-F-F boundary conditions. This is done so that the effective area of the specimen for modal testing is maintained at $150 \mathrm{~mm} \times 150 \mathrm{~mm}$ for both F-F-F-F and C-F-F-F boundary conditions. The specimen for C-F-F-F boundary condition is fixed onto the fixture using four $6 \mathrm{~mm}$ threaded bolts as shown in Figure 2. On each of the rectangular specimen the area of $150 \mathrm{~mm} * 150 \mathrm{~mm}$ is divided and 49 grid points are marked as shown in Figure-2.

\begin{tabular}{|c|}
\hline 1 \\
\hline 2 \\
\hline 3 \\
\hline 4 \\
\hline 5 \\
\hline 6 \\
\hline 7 \\
\hline 8 \\
\hline 9 \\
\hline 10 \\
\hline
\end{tabular}

G

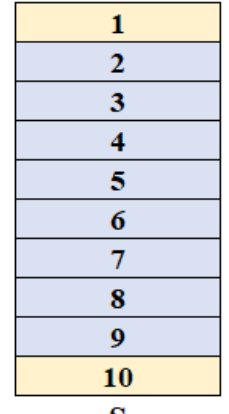

$\mathrm{S}$

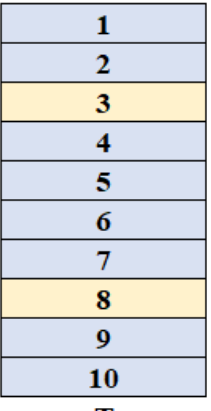

T

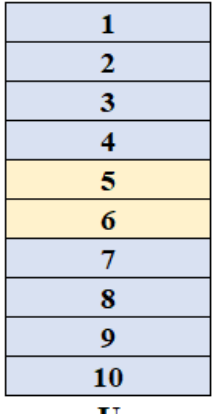

$\mathbf{U}$

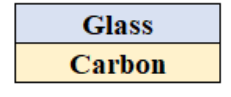

Fig-1: Laminates with different stacking sequence

Table-1: Laminates Fabricated

\begin{tabular}{|l|l|l|l|l|l|}
\hline $\begin{array}{l}\text { Sl. } \\
\text { No }\end{array}$ & Material & $\begin{array}{l}\text { Laminate } \\
\text { naming }\end{array}$ & Nos of Layers & Stacking Sequence & Details \\
\hline 1 & GFRP & G2 & 10 & {$[$ G-G-G-G-G]s } & $\begin{array}{l}\text { All } 10 \text { plies are glass fibers and all fibers } \\
\text { orientated at } 45^{0} \text { in laminate }\end{array}$ \\
\hline 2 & Hybrid & S2 & 10 & {$[$ C-G-G-G-G]s } & $\begin{array}{l}\text { Carbon layer stacked at } 1^{\text {st }} \text { and } 10^{\text {th }} \text { position } \\
\text { in the laminate All fibers orientated at } 45^{0 .}\end{array}$ \\
\hline 3 & Hybrid & T2 & 10 & {$[$ G-G-C-G-G]s } & $\begin{array}{l}\text { Carbon layer stacked at } 3^{\text {rd }} \text { and } 8^{\text {th }} \text { position } \\
\text { in the laminate All fibers orientated at } 45^{0}\end{array}$ \\
\hline 4 & Hybrid & U2 & 10 & [G-G-G-G-C]s & $\begin{array}{l}\text { Carbon layer stacked at } 5^{\text {th }} \text { and } 6^{\text {th }} \text { position } \\
\text { in the laminate All fibers orientated at } 45^{0}\end{array}$ \\
\hline
\end{tabular}

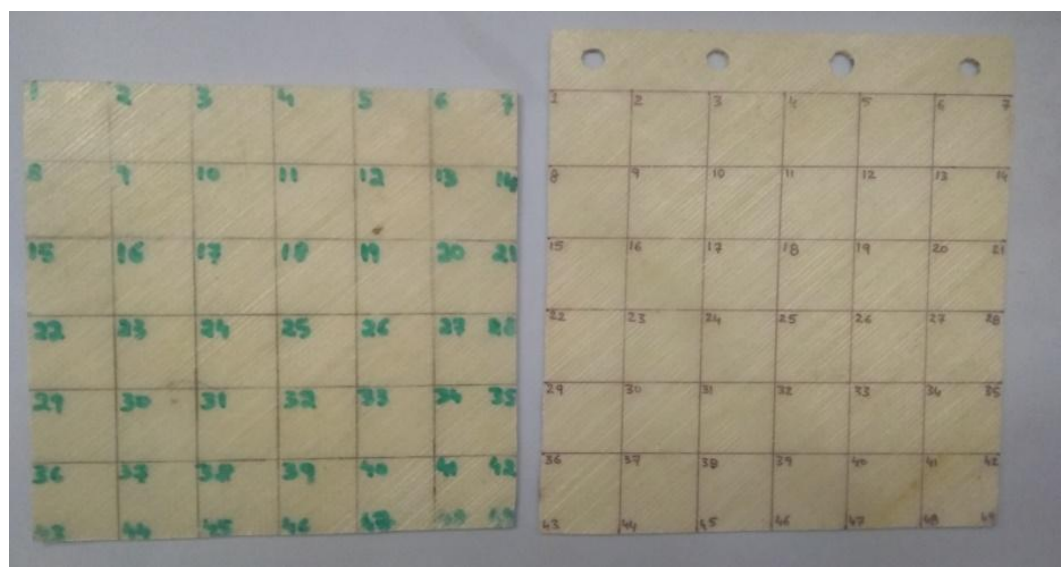

Fig-2: Specimens for C-F-F-F and F-F-F-F fixation with 49 grid points

\section{EXPERIMENTAL SETUP FOR VIBRATION ANALYSIS}

Traditional experimental modal analysis method of strike method is used for exciting the composite laminates. On the composite test specimen
49 grid points are marked on the area of $150 * 150 \mathrm{~mm}$ to get a good response. Each of these 49 grid point is triggered on the specimen using a piezoelectric hammer and the response is measured by an accelerometer placed below the specimen. The piezoelectric hammer 
Nagabhushan V Pujar et al; Saudi J Eng Technol, Jan, 2021; 6(1): 1-8.

generates a voltage for the applied impact force which is then calibrated to force. The accelerometer is connected to Data Acquisition System (DAQ). The information received is shared with the DAQ software which processes the data and displays the frequency, damping values and mode shape. To get superior response, each point of the specimen is excited eight times and average value is taken so as to nullify any external effect.
Experimental Setup and Test Procedure for F-F-F-F boundary condition

The experimental modal analysis test facility consists of an impact hammer, an accelerometer, a 4channel FFT analyzer along with data acquisition software. While conducting modal analysis, to simulate the Free-Free-Free-Free (F-F-F-F) boundary conditions the rectangular specimen is suspended from a frame by using a soft elastic thread as shown in Figure-3. The specimen which has been suspended by elastic thread is excited at each of the grid point by means of the impact hammer and the resulting response are measured by an accelerometer mounted on the specimen.

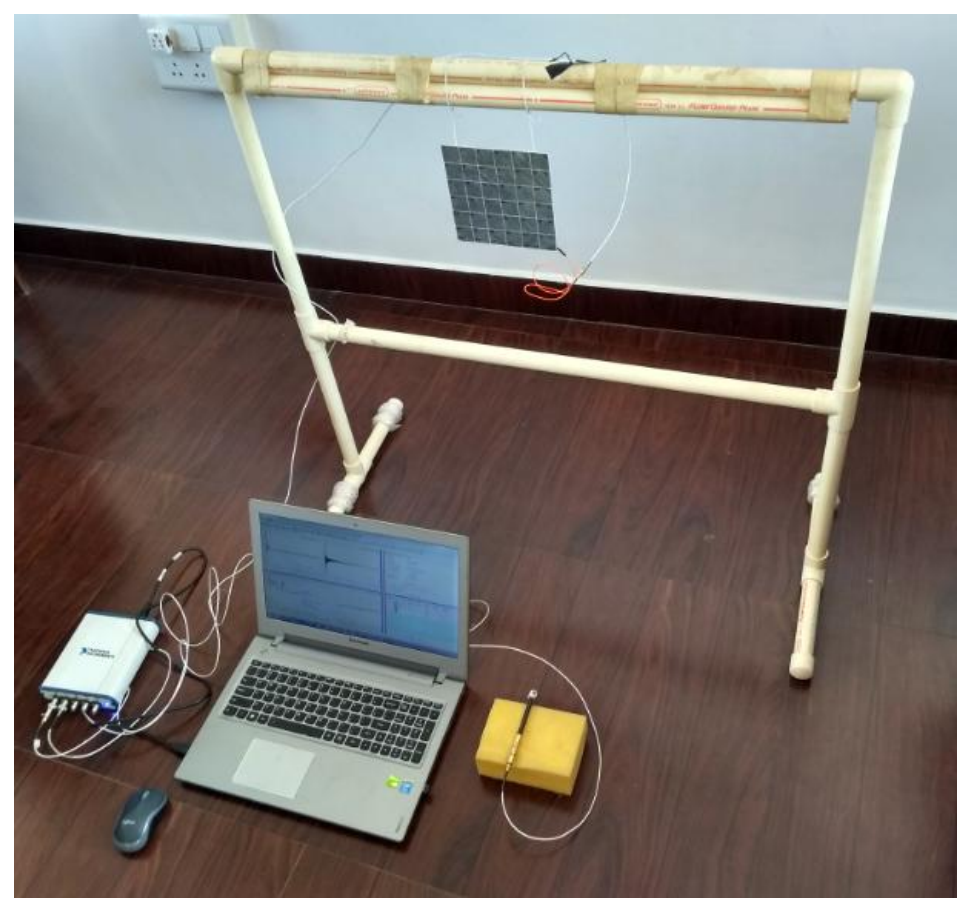

Fig-3: Experimental setup for F-F-F-F boundary condition

\section{Experimental Setup and Test Procedure for C-F-F-F boundary condition}

While conducting modal analysis, to simulate Constrained-Free-Free-Free (C-F-F-F) boundary condition a test fixture as shown in Figure-4 is used.
The composite test specimen is secured to the fixture by means of 4 threaded bolts. The specimen is excited at each of the 49 grid point by using an impact hammer and the resulting response is measured by an accelerometer mounted below the specimen.

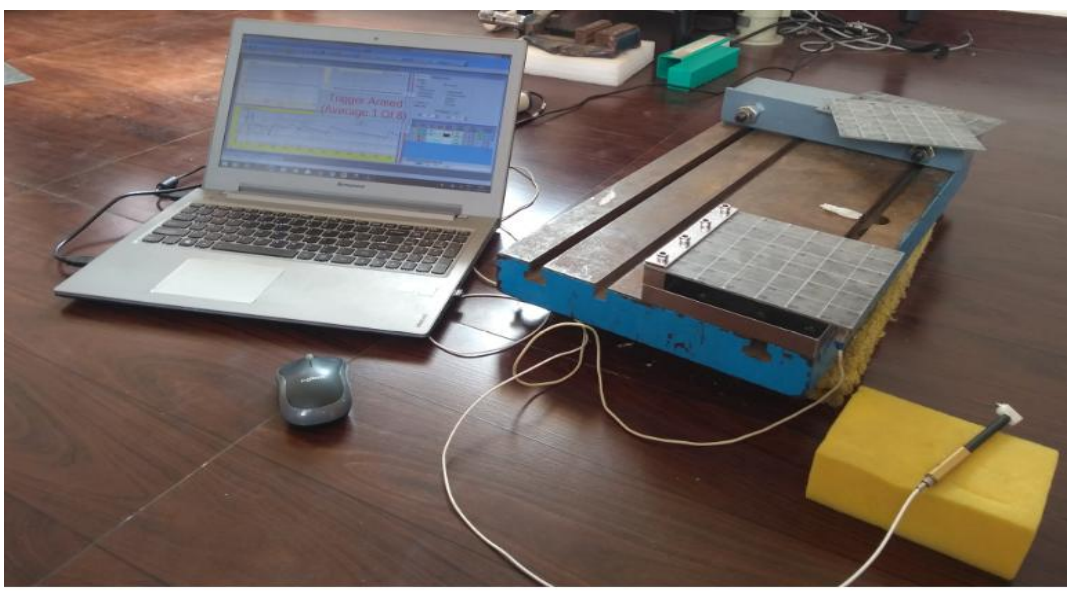

Fig-4: Experimental setup for C-F-F-F boundary condition 
Nagabhushan V Pujar et al; Saudi J Eng Technol, Jan, 2021; 6(1): 1-8.

\section{RESULTS AND DISCUSSION}

In this investigation, the experimental modal analysis is conducted for composite laminates with fiber directions of $45^{\circ}$ and for two different boundary conditions ie F-F-F-F and C-F-F-F. First three natural frequencies and \% damping were determined experimentally for all composite specimens and the results are discussed in the next sections.
Modal analysis with F-F-F-F boundary condition $\&$ $45^{\circ}$ fiber orientation

The frequencies and \% damping values obtained from the modal analysis for the fiber orientation of $45^{\circ}$ are shown in the Table-2. The graphs showing the variation of frequency and damping are shown in Figure 5 and 6.

Table-2: Modal parameters for F-F-F-F

\begin{tabular}{|c|c|c|c|c|c|}
\hline Laminates & Fiber Orientation & Modal Parameter & $1^{\text {st }}$ Mode & $2^{\text {nd }}$ Mode & $3^{\text {rd }}$ Mode \\
\hline \multirow[t]{2}{*}{$\mathrm{G} 2$} & \multirow[t]{2}{*}{45} & Frequency, $\mathrm{Hz}$ & 183 & 238 & 367 \\
\hline & & $\%$ Damping & 1.61 & 0.57 & 0.81 \\
\hline \multirow[t]{2}{*}{$\mathrm{S} 2$} & \multirow[t]{2}{*}{45} & Frequency, $\mathrm{Hz}$ & 211 & 266 & 440 \\
\hline & & $\%$ Damping & 0.34 & 1.24 & 0.87 \\
\hline \multirow[t]{2}{*}{$\mathrm{T} 2$} & \multirow[t]{2}{*}{45} & Frequency, $\mathrm{Hz}$ & 205 & 364 & 575 \\
\hline & & $\%$ Damping & 0.28 & 0.29 & 0.37 \\
\hline \multirow[t]{2}{*}{$\mathrm{U} 2$} & \multirow[t]{2}{*}{45} & Frequency, $\mathrm{Hz}$ & 203 & 334 & 550 \\
\hline & & $\%$ Damping & 0.30 & 0.50 & 0.40 \\
\hline
\end{tabular}

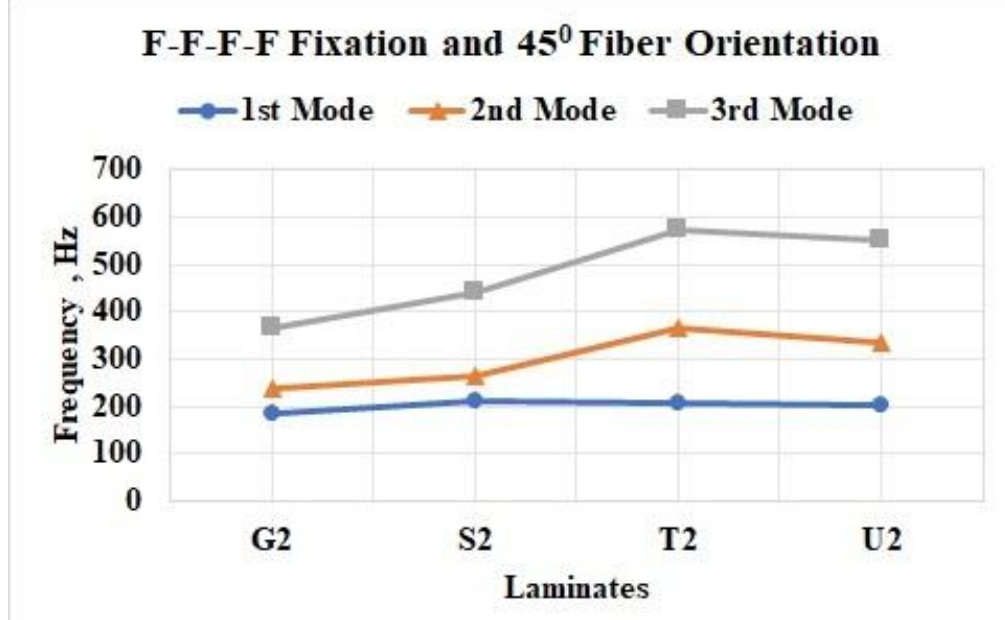

Fig-5: Frequencies for F-F-F-F

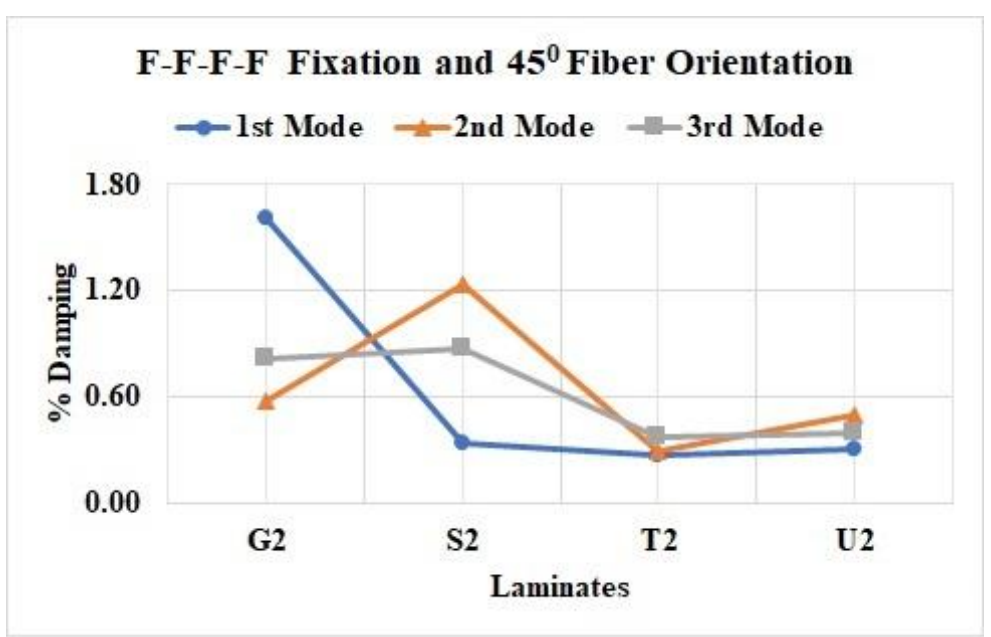

Fig-6: Damping for F-F-F-F

It is observed for F-F-F-F boundary conditions, the frequency shows significant variation with hybridization. For S2 laminate the frequency increases by $15.4 \%$ for the $1^{\text {st }}$ mode compared to the
G2 laminate. In S2 laminate the carbon fibers are on the outside of the laminate and hence the frequencies are higher compared to neat glass laminate. The frequency 
Nagabhushan V Pujar et al; Saudi J Eng Technol, Jan, 2021; 6(1): 1-8.

increase by $12.2 \%$ and $11.1 \%$ are seen for laminates $\mathrm{T} 2$ and $\mathrm{U} 2$ compared to the $\mathrm{G} 2$ laminate for the $1^{\text {st }}$ mode.

For mode 2, the frequency of S2 laminate the frequency increases by $11.65 \%$ compared to the $\mathrm{G} 2$ laminate. The frequency increases by $52.9 \%$ and $40.2 \%$ for laminates T2 and U2 compared to the G2 laminate for the $2^{\text {nd }}$ mode.

For mode 3, the frequency of S2 laminate increases by $19.8 \%$ compared to the $\mathrm{G} 2$ specimen. The frequency increases by $56.6 \%$ and $49.2 \%$ for laminates $\mathrm{T} 2$ and U2 compared to the G2 laminate for the $3^{\text {nd }}$ mode.

As the carbon fiber are stacked towards the center of the laminate the value of the frequency reduces. The trend of variation in frequency is similar for all the 3 modes.

Laminate S2 shows decrease in damping of $78.8 \%$ for $1^{\text {st }}$ mode. Laminate $\mathrm{T} 2 \& \mathrm{U} 2$ shows decrease in damping of $82.8 \% \& 81.2 \%$ for $1^{\text {st }}$ mode. For $2^{\text {nd }}$ mode laminate $\mathrm{S} 2$ shows increase in damping of 116.1 $\%$. Laminate $\mathrm{T} 2$ shows decrease in damping of $49.7 \%$ and U2 shows decrease in damping of $13.6 \%$ compared to neat $\mathrm{G} 2$ laminate.

For $3^{\text {rd }}$ mode laminate $\mathrm{S} 2$ shows increase in damping of $7.1 \%$. Laminate $\mathrm{T} 2$ shows decrease in damping of $54.7 \%$ and U2 shows decrease in damping of $50.6 \%$ compared to neat G2 laminate. The improvement in damping is not seen in hybrid laminates due to hybridization.

\section{Modal analysis with C-F-F-F boundary condition \& $45^{\circ}$ fiber orientation}

The frequencies and \% damping values obtained from the modal analysis for the fiber orientation of $45^{\circ}$ are shown in the Table-3. The graphs showing the variation of frequency and damping are shown in Figure 7 and 8.

Table-3: Modal parameters for C-F-F-F

\begin{tabular}{|c|c|c|c|c|c|}
\hline Laminates & Fiber Orientation & Modal Parameter & $1^{\text {st }}$ Mode & $2^{\text {nd }}$ Mode & $3^{\text {rd }}$ Mode \\
\hline \multirow[t]{2}{*}{$\mathrm{G} 2$} & \multirow[t]{2}{*}{45} & Frequency, $\mathrm{Hz}$ & 43 & 123 & 263 \\
\hline & & $\%$ Damping & 0.71 & 0.74 & 0.51 \\
\hline \multirow[t]{2}{*}{ S2 } & \multirow[t]{2}{*}{45} & Frequency, $\mathrm{Hz}$ & 49 & 135 & 314 \\
\hline & & $\%$ Damping & 1.83 & 0.62 & 2.02 \\
\hline \multirow[t]{2}{*}{$\mathrm{T} 2$} & \multirow[t]{2}{*}{45} & Frequency, $\mathrm{Hz}$ & 50 & 133 & 307 \\
\hline & & $\%$ Damping & 0.54 & 1.52 & 1.89 \\
\hline \multirow[t]{2}{*}{$\mathrm{U} 2$} & \multirow[t]{2}{*}{45} & Frequency, $\mathrm{Hz}$ & 42 & 117 & 279 \\
\hline & & \% Damping & 1.01 & 0.39 & 0.76 \\
\hline
\end{tabular}

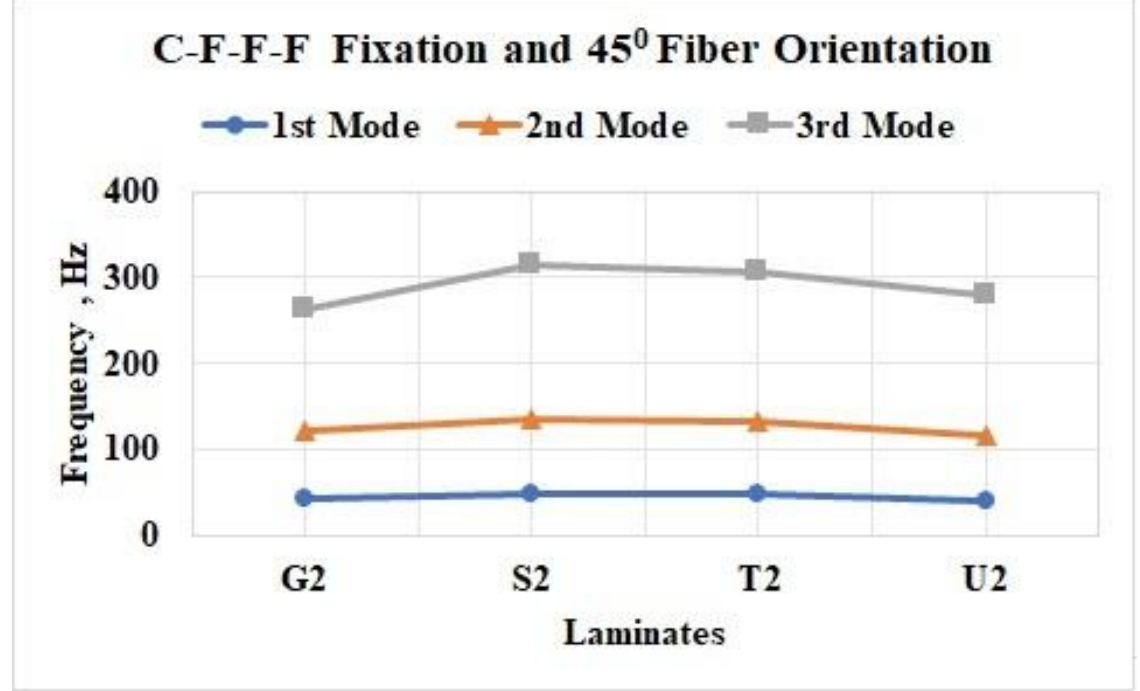

Fig-7: Frequencies for C-F-F-F 


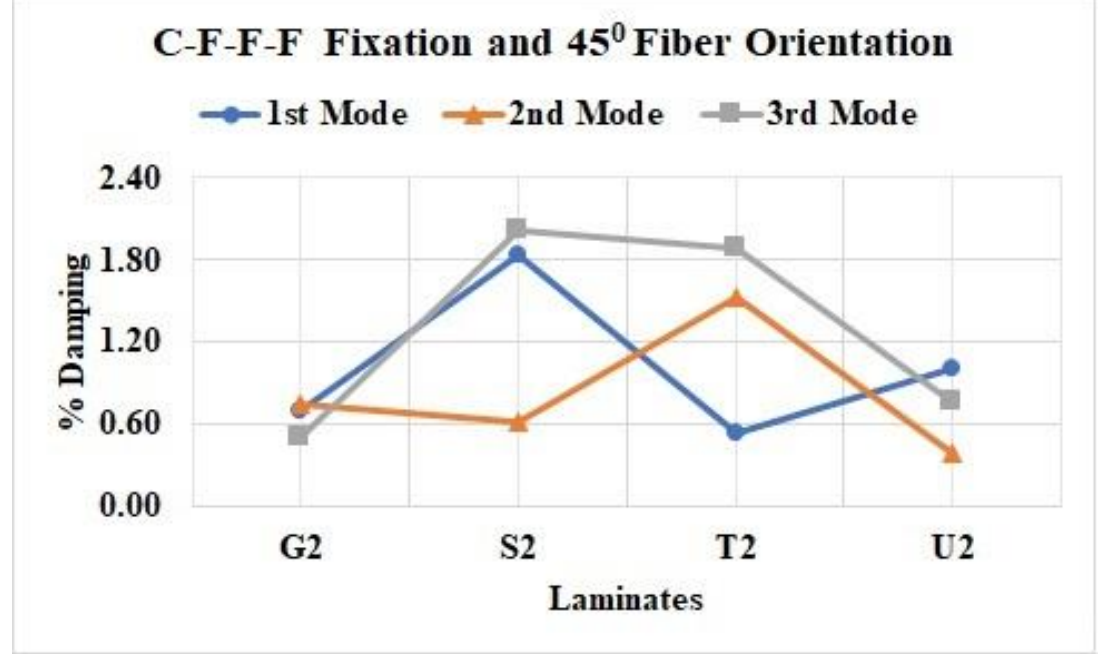

Fig-8: Damping for C-F-F-F

It is observed that frequency showed significant variation with hybridization. For S2 laminate the frequency increases by $14.2 \%$ for the $1^{\text {st }}$ mode compared to the G2 specimen. For T2 laminate the frequency increases by $17 \%$ for the $1^{\text {st }}$ mode compared to the $\mathrm{G} 2$ specimen.

For mode 2, the frequency of S2 laminate the frequency increases by $9.9 \%$ compared to the G2 specimen. For T2 laminate the frequency increases by $8.4 \%$ compared to the $\mathrm{G} 2$ specimen.

For mode 3, the frequency of S2 laminate the frequency increases by $19.2 \%$ compared to the G2 specimen. The frequency increases by $16.7 \%$ and $6.21 \%$ for $\mathrm{T} 2$ \& U2 laminates compared to the G2 laminate.

Laminate S2 shows increase in damping of $159.36 \%$ for $1^{\text {st }}$ mode. Laminate U2 shows increase in damping of $42.5 \%$ for $1^{\text {st }}$ mode. Laminate T2 shows increase in damping of $104.48 \%$ for $2^{\text {nd }}$ mode, S2 and U2 shows decrease in damping by $16.4 \%$ and $47.9 \%$.

The damping exhibited by hybrid laminates is highest for the $3^{\text {rd }}$ mode compared to other two modes. Laminate S2, T2, U2 shows increase in damping of $298.7 \%, 272.2 \%$ and $50.7 \%$ compared to G2 laminate.

\section{CONCLUSION}

The dynamic properties of symmetric interlayer hybrid composite reinforced with $0.5 \%$ wt of graphene oxide were investigated and compared with neat E-glass/epoxy composite. The outcome of the experimental research work are listed below:

- The natural frequencies obtained experimentally were of higher magnitude for specimens with F-FF-F boundary condition compared to the specimens with C-F-F-F boundary condition.
- The boundary conditions (fixations) used in the experimental modal analysis have significant influence on the dynamic properties.

- With C-F-F-F boundary conditions, nano-modified hybrid laminates $\mathrm{S} 2$ and $\mathrm{T} 2$ with $45^{\circ}$ fiber orientation showed higher frequency than the neat glass laminate G2. The damping was higher for nano-modified hybrid laminates for the $3^{\text {rd }}$ mode compared to the neat glass laminate. The damping was seen to be highest for S2 laminate at the $3^{\text {rd }}$ mode.

- With F-F-F-F boundary conditions, the variation in frequency is seen more in nano-modified hybrid laminate when compared to neat glass G2 laminate. Nano-modified hybrid laminates exhibit higher damping for $2^{\text {nd }}$ mode when compared to other modes.

- Nano-modification of interlayer of glass/carbon with graphene oxide displayed enhanced damping at higher modes.

- From the experiments it is observed that the hybridization technique has an influence on the dynamic properties. It can be investigated further with different percentage of GO inclusion.

\section{ACKNOWLEDGEMENTS}

Authors thankfully acknowledge the Management, Principal and Head of the Department of Mechanical Engineering, R V College of Engineering for their constant encouragement and support in carrying out this work.

\section{DECLARATION OF CONFLICTING INTERESTS}

The author(s) declared no potential conflicts of interest with respect to the research, authorship, and/or publication of this article.

\section{FUNDING}

The author(s) received no financial support for the research, authorship, and/or publication of this article. 
Nagabhushan V Pujar et al; Saudi J Eng Technol, Jan, 2021; 6(1): 1-8.

\section{REFERENCES}

1. Swolfs, Y., Gorbatikh, L., \& Verpoest, I. (2014). Fibre hybridisation in polymer composites: a review. Composites Part A: Applied Science and Manufacturing, 67, 181-200.

2. Swolfs, Y., Gorbatikh, L., \& Verpoest, I. (2013). Stress concentrations in hybrid unidirectional fibre-reinforced composites with random fibre packings. Composites Science and Technology, 85, 10-16.

3. Duc, F., Bourban, P. E., Plummer, C. J. G., \& Månson, J. A. (2014). Damping of thermoset and thermoplastic flax fibre composites. Composites Part A: Applied Science and Manufacturing, 64, 115-123.

4. Kareem, A., \& Gurley, K. (1996). Damping in structures: its evaluation and treatment of uncertainty. Journal of wind engineering and industrial aerodynamics, 59(2), 131-157.

5. Finegan, I. C., \& Gibson, R. F. (1999). Recent research on enhancement of damping in polymer composites. Composite structures, 44(2-3), 89-98.

6. Oya, N., \& Hamada, H. (1996). Effects of Reinforcing Fibre Properties on Various Mechanical Behaviors of Unidirectional Carbon/Epoxy Laminates. Sci Eng Compost Mater. 5:105-130.

7. Cramer, D. R., \& Taggart D. F. (2002). Design and Manufacture of an Affordable AdvancedComposite Automotive Body Structure, In Proceedings of the 19th International Battery, Hybrid and Fuel Cell Electric Vehicle Symposium and Exhibition, Busan, Korea, 19-23.

8. Manders, P W., \& Bader, M. G. (1981). The Strength of Hybrid Glass/Carbon Fibre, Composites. J Mater Sci. 16:2233-2245.

9. Zweben, C. (1977). Tensile Strength of Hybrid Composites. J Mater Sci. 1 12:1325-1337.

10. Kalnin, I. L. (1972). Evaluation of Unidirectional Glass-Graphite Fiber/Epoxy Resin Composites, Compost. Mater. ASTM Int.

11. Talib, A. A., Ali, A., Badie, M. A., Lah, N. A. C., \& Golestaneh, A. F. (2010). Developing a hybrid, carbon/glass fiber-reinforced, epoxy composite automotive drive shaft. Materials \& Design, 31(1), 514-521.

12. Susilo, D. D., Hafid, N., \& Raharjo, W. W. (2014). The Effect of Fiber Orientation on the Dynamic Characteristic of the Carbon-Glass Fiber Hybrid Composite.

13. Nayak, N., Meher, S., \& Sahu, S. K. (2013). Experimental and numerical study on vibration and buckling characteristics of glass-carbon/epoxy hybrid composite plates. In Proc. of Int. Conf. on Advances in Civil Engineering, AETACE (pp. 888-895).

14. Murugan, R., Ramesh, R., \& Padmanabhan, K. (2014). Investigation on static and dynamic mechanical properties of epoxy based woven fabric glass/carbon hybrid composite laminates. Procedia Engineering, 97, 459-468.

15. Murugan, R., Ramesh, R., \& Padmanabhan, K. (2016). Investigation of the mechanical behavior and vibration characteristics of thin walled glass/carbon hybrid composite beams under a fixed-free boundary condition. Mechanics of Advanced Materials and Structures, 23(8), 909916.

16. Liu, Q., Zhou, X., Fan, X., Zhu, C., Yao, X., \& Liu, Z. (2012). Mechanical and thermal properties of epoxy resin nanocomposites reinforced with graphene oxide. Polymer-Plastics Technology and Engineering, 51(3), 251-256.

17. Guan, L. Z., Wan, Y. J., Gong, L. X., Yan, D., Tang, L. C., Wu, L. B., ... \& Lai, G. Q. (2014). Toward effective and tunable interphases in graphene oxide/epoxy composites by grafting different chain lengths of polyetheramine onto graphene oxide. Journal of Materials Chemistry A, 2(36), 15058-15069.

18. Galpaya, D., Wang, M., George, G., Motta, N., Waclawik, E., \& Yan, C. (2014). Preparation of graphene oxide/epoxy nanocomposites with significantly improved mechanical properties. Journal of Applied Physics, 116(5), 053518.

19. Pathak, A. K., Borah, M., Gupta, A., Yokozeki, T., \& Dhakate, S. R. (2016). Improved mechanical properties of carbon fiber/graphene oxide-epoxy hybrid composites. Composites Science and Technology, 135, 28-38.

20. Pujar, N. V., Nanjundaradhya, N. V., \& Sharma, R. S. (2018, April). Effect of graphene oxide nano filler on dynamic behaviour of GFRP composites. In AIP Conference Proceedings (Vol. 1943, No. 1, p. 020107). AIP Publishing LLC.

21. Rafiee, M., Nitzsche, F., \& Labrosse, M. R. (2019). Fabrication and experimental evaluation of vibration and damping in multiscale graphene/fiberglass/epoxy composites. Journal of Composite Materials, 53(15), 2105-2118.

22. Tang, X., \& Yan, X. (2020). A review on the damping properties of fiber reinforced polymer composites. Journal of Industrial Textiles, 49(6), 693-721. 